\title{
Tariffs, quality reversals and exit in vertically differentiated industries
}

\author{
Iñigo Herguera ${ }^{\mathrm{a}}$, Praveen Kujal ${ }^{\mathrm{b}, *}$, Emmanuel Petrakis $^{\mathrm{c}}$ \\ ${ }^{\mathrm{a}}$ Universidad Complutense, Complutense, Spain \\ ${ }^{\mathrm{b}}$ Universidad Carlos III de Madrid, Departamento de Economia, Calle Madrid 126-128, \\ 28903 Getafe, Madrid, Spain \\ ${ }^{\mathrm{c}}$ University of Crete, Crete, Greece
}

\begin{abstract}
In a vertically differentiated industry a domestic and a foreign firm first choose the quality of their goods and then compete in quantities, or prices, in the home market. We investigate the cases in which a tariff is chosen before, or after, the firms' quality decision. These cases are referred to as the ex-ante and the ex-post game, respectively. Optimal ex-post tariffs are positive and ensure that the domestic firm always produces the high quality good. The optimal ex-ante tariff is prohibitive and welfare under domestic monopoly is lower than under ex-post tariffs, unless firms compete in prices and the domestic firm is high quality.
\end{abstract}

Keywords: Vertical differentiation; Import tariffs; Quality reversals; Exit

JEL classification: $\mathrm{F} 12 ; \mathrm{F} 13 ; \mathrm{L} 13$

\section{Introduction}

In this paper we study the effect of import tariffs in a vertically differentiated industry where a foreign and a domestic firm sell in the home market. The firms first simultaneously choose the quality of their goods and then compete in the

*Corresponding author Tel: +34-91-624-9651; fax: +34-91-624-9875

E-mail address: kujal@eco uc3m es (P Kujal) 
market. The government sets the tariff level before, or after, the firms' quality decision. These cases are referred to as the ex-ante and the ex-post game, respectively. We show that in the ex-post tariff game the domestic firm always produces the high quality good independently of whether competition is in prices, or quantities. The optimal ex-ante tariff is prohibitive and welfare under domestic monopoly is lower than under ex-post tariffs, unless firms compete in prices and the domestic firm is high quality. A tariff has important effects on long run quality investment and market structure. In response to any tariff a foreign firm always invests less in quality. The domestic firm, however, lowers (increases) quality investment if the tariff receiving foreign firm is low (high) quality.

Until recently the strategic trade policy literature has mainly focussed on imperfectly competitive homogenous, or horizontally differentiated, industries. The main insights from this literature are that strategic trade policy is sensitive to the patterns of competition and that optimal policy can vary depending on the mix of the policy instruments that one considers. The use of these instruments may be to a government's advantage, ${ }^{2}$ although sometimes policy instruments are adopted even though they may be jointly suboptimal. ${ }^{3,4}$ In all these models the government decides on the level of the policy instrument before firms decide on their market strategies. These models thus implicitly assume government commitment to a specific policy level. Subsequent research on strategic trade policy has investigated the effect of the timing of moves on the choice of trade policies and domestic welfare. The principal contribution of this literature is the finding that optimal trade policy is sensitive to the timing of policy choice and that ex-ante subsidies are generally welfare improving.

There are several reasons why vertical product differentiation models are worth analyzing. First, there is evidence that intra industry trade characterized by different levels of quality is a significant proportion of trade (see Greenaway et al., 1990 among others). Given this it is surprising that little attention has been paid to

\footnotetext{
${ }^{1}$ We use Neary's (1991) terminology.

${ }^{2}$ Brander and Spencer (1984) show that an activist government can use tariffs as a welfare improving policy tool in an imperfectly competitive domestic market where a foreign and a domestic firm compete in quantities. They show that the decrease in consumer surplus is less than the joint increase in domestic firm's profits and tariff revenues.

${ }^{3}$ Brander and Spencer (1985), using a third-market model, show that the noncooperative equilibrium is characterized by positive production subsidies for both the exporting countries. Joint welfare of the producing nations would rise if the subsidy levels were reduced by both governments. Eaton and Grossman (1986) show that under Bertrand competition the optimal policy is a tax on exports.

${ }^{4}$ Analysing anti-dumping and countervailing duties, Dixit (1988) has shown that the trade policy equilibrium implies both positive subsidies and tariffs. The domestic government can attain the first best outcome by using a tariff on imports and a subsidy towards domestic production to eliminate the oligopoly distortion and to shift rents to the domestic firm. If the government is restricted to using only tariffs then the (second-best) optimal tariff exceeds its fully optimal value. Also see Collie (1991). Note, unlike Dixit we do not consider multiple instruments.

${ }^{5}$ See for instance, Leahy and Neary $(1994,1996,1999)$.
} 
strategic trade policy in vertically differentiated industries. Second, these models enable us to analyze firm investment in quality, a feature absent from horizontal product differentiation models. Commitment to quality reflects an important characteristic of oligopolistic markets where firms invest in a long run ${ }^{6}$ strategic variable prior to the market competition stage.

Quality levels being endogenous, two asymmetric pure strategy equilibria arise in a duopolistic market whenever consumers have heterogenous tastes in quality. That is, one high and one low quality firm emerge in equilibrium. Investment in a long run variable (i.e. quality) and the existence of asymmetric qualities raises interesting questions for trade policy. Besides affecting investment in quality, trade policy also affects market structure. It can alter market structure by forcing the exit of the foreign firm, or result in quality switching (due to which the domestic firm always produces the high quality good). Quality reversals and exit due to government policies are unique to the vertical product differentiation models.

In our model, quality switching may occur when the domestic government chooses its tariff level ex-post. Knowing that the higher its quality level, the higher the tariff will be ex-post, the foreign firm has little incentive to invest in quality and is always the low quality producer in the ex-post game. This is due to the fact that the domestic government moves second, and since investment in quality is sunk, the government can safely expropriate gross profits of the foreign firm by setting a high tariff level. Therefore, to guarantee positive net profits, a foreign firm (producing high quality under free trade), switches positions in the quality ladder and becomes the low quality producer instead.

The optimal ex-ante tariff is the prohibitive tariff that forces the exit of the foreign firm. A domestic monopoly is always obtained except for the case in which firms compete in prices and the domestic firm is high quality. ${ }^{8}$ Ex-post tariffs are always lower than ex-ante tariffs because the foreign firm, having a first mover advantage, can induce a lower tariff level by strategically investing less in quality.

Contrary to what has been shown for output subsidies, ${ }^{9}$ domestic welfare under ex-post tariffs is higher than under both ex-ante tariffs and free trade (except for the case pointed out above). This is due to the fact that in our model the government has at its disposal only one instrument to achieve three targets, i.e. to shift rents towards the domestic firm and to correct for the output and the quality investment distortions due to the firms' market power. The government has a

\footnotetext{
${ }^{6}$ Trade policy instruments affect short run variables, such as prices and quantities, and also affect long run variables such as quality. For a discussion of the short- and long-term view of the rent transfer effect, and the difference between them, see Grossman (1988).

${ }^{7}$ This is a standard result in the literature on vertical differentiation, see e.g. Motta (1993), Tirole (1989), Shaked and Sutton $(1982,1983,1984)$.

${ }^{8}$ In this case, the optimal ex-ante tariff is positive and allows for low quality imports.

${ }^{9}$ See, for example, Neary (1991), Leahy and Neary (1994, 1996, 1999).
} 
second mover advantage in the ex-post game and achieves greater welfare by setting its tariff level after the firms' quality decisions. ${ }^{10}$

Another important result in our paper is the effect of tariffs on quality investment by both the foreign and the domestic firm. Independently of whether a foreign firm produces low, or high, quality, it always invests less in quality in response to any (ex-ante, or ex-post) tariff. ${ }^{11}$ The domestic firm invests less (more) in quality if the tariff receiving foreign firm produces the low (high) quality good. Tariffs soften competition for the domestic firm and affect long run variables, such as quality. Subsequently, profits for the domestic (foreign) firm increase (decrease) under any tariff.

In Section 2, we present the vertical product differentiation model under quantity competition with the free trade equilibrium quality, quantity, and welfare outcomes. In Section 3, the ex-post tariff game is analyzed and its outcome is compared to free trade. In Section 4, the ex-ante tariff game is analyzed and its outcome is compared to the ex-post game and free trade. In Section 5, we briefly discuss the results under Bertrand competition. Section 6 concludes. A detailed treatment of the Bertrand case is included in Appendix A.

\section{The basic model}

There are two countries, one foreign and one domestic. Each has a firm that produces a vertically differentiated good to sell in the domestic market. Firms first simultaneously select the quality of their goods and then compete in the market by (simultaneously) setting their quantities. Quality is endogenous and $s_{1}$ denotes the high quality and $s_{2}$ the low quality offered in the market $\left(s_{1} \geq s_{2}\right)$. We concentrate on the effects of import tariffs in the domestic market alone. ${ }^{12}$ There is a continuum of consumers in the domestic market, each identified by his taste parameter $\theta$, which is uniformly distributed over the interval $[0, \bar{\theta}]$ with density one; $\bar{\theta}$ then represents the size of the market. Each consumer has unitary demand for the good and a consumer with parameter $\theta$ has utility:

$$
U=\left\{\begin{array}{cc}
\left(\theta s_{i}-p\right) & \text { if he buys one unit of the good of quality } s_{i} \\
0 & \text { otherwise }
\end{array}\right.
$$

\footnotetext{
${ }^{10}$ It is important also to note that in this paper we do not consider tariffs ex-ante contingent on the quality of imports.

${ }^{11}$ In a similar model and in response to a quantity restriction, quality downgrading is also shown (Herguera et al., 2000).

${ }^{12}$ This is a home market model as in Dixit (1988) and Collie (1991).
} 
To derive the demand for each type of good, we first define the taste parameter $\theta_{12}$ of the consumer who is indifferent between buying the high, or low, quality good, $\theta_{12}=\left[\left(p_{1}-p_{2}\right) /\left(s_{1}-s_{2}\right)\right]$ (assuming $\left.p_{1}>p_{2}\right)$. The consumer indifferent between buying the low quality good and not buying at all has the taste parameter $\theta_{02}=p_{2} / s_{2}$. All the consumers for whom $\bar{\theta} \geq \theta \geq \theta_{12}$ purchase the good with quality $s_{1}$ and all consumers for whom $\theta_{12} \geq \theta \geq \theta_{02}$ purchase quality $s_{2}$ Those described by $\theta<\theta_{02}$ do not buy the good at all. Hence the demands for the high and low quality good are, respectively:

$$
x_{1}\left(p_{1}, p_{2}\right)=\bar{\theta}-\frac{p_{1}-p_{2}}{s_{1}-s_{2}} ; \quad x_{2}\left(p_{1}, p_{2}\right)=\frac{p_{1}-p_{2}}{s_{1}-s_{2}}-\frac{p_{2}}{s_{2}}
$$

with the respective inverse demands:

$$
p_{1}\left(x_{1}, x_{2}\right)=\bar{\theta} s_{1}-x_{1} s_{1}-x_{2} s_{2} ; \quad p_{2}\left(x_{1}, x_{2}\right)=\left(\bar{\theta}-x_{1}-x_{2}\right) s_{2}
$$

Firm $i$ 's cost function is $C\left(s_{i}, x_{i}\right)=c x_{i}+\frac{s_{i}^{2}}{2}$, where $x_{i}$ represents its output and $s_{i}$ the quality of its good. The marginal cost of production, $c$, is constant and independent of quality. Without loss of generality, we assume that marginal cost, $c$, is zero for both the domestic and the foreign firm. Quality costs are fixed costs and there are increasing costs of quality improvement. This specification captures the distinctive characteristics of (pure) vertical product differentiation models. Shaked and Sutton (1983) define a purely vertically differentiated industry as one in which the costs of quality improvement fall primarily into fixed costs and involve only a modest, or no, increase in unit variable costs. Quality costs borne in the first stage are treated as sunk in the market competition stage.

\subsection{Free trade equilibrium}

We start by briefly presenting the outcome for the benchmark case. Under free trade, firms first simultaneously select their quality level and then (simultaneously) choose their quantities. Working backwards, in the last stage, for any given pair of qualities $\left(s_{1}, s_{2}\right)$, firm $i$ chooses its quantity to maximize its profits, $p_{i}\left(x_{i}, x_{j}\right) x_{i}-\frac{s_{i}^{2}}{2}$, given the quantity of its rival $x_{j}$. From the first order conditions (foc), we get the equilibrium quantities:

$$
x_{1}^{F T}\left(s_{1}, s_{2}\right)=\frac{2 s_{1}-s_{2}}{4 s_{1}-s_{2}} \bar{\theta} ; \quad x_{2}^{F T}\left(s_{1}, s_{2}\right)=\frac{s_{1}}{4 s_{1}-s_{2}} \bar{\theta}
$$

Equilibrium profits are, $\pi_{i}^{F T}\left(s_{1}, s_{2}\right)=s_{i}\left(x_{i}^{F T}\right)^{2}-\frac{s_{i}^{2}}{2}, i=1,2$.

In the first stage, taking the quality of its rival $s_{j}$ as given, firm $i$ chooses $s_{i}$ to maximize $\pi_{i}^{F T}\left(s_{i}, s_{j}\right)$. Setting $\lambda=\frac{s_{2}}{s_{1}}$, dividing the first order conditions, and manipulating we get the equilibrium qualities, quantities, profits, and domestic welfare under free trade (for details see Motta, 1993): 


\begin{tabular}{lll}
\hline$s_{1}^{F T}=0.25194 \bar{\theta}^{2}$ & $s_{2}^{F T}=0.09022 \bar{\theta}^{2}$ & $\bar{s}=0.191 \bar{\theta}^{2}$ \\
\hline$x_{1}^{F T}=0.4508 \bar{\theta}$ & $x_{2}^{F T}=0.2746 \bar{\theta}$ & $C S^{F T}=0.04017 \bar{\theta}^{4}$ \\
\hline$\pi_{1}^{F T}=0.01946 \bar{\theta}^{4}$ & $\pi_{2}^{F T}=0.00273 \bar{\theta}^{4}$ & $T W_{f h}^{F T}=0.04290 \bar{\theta}^{4}$ \\
& & $T W_{f l}^{F T}=0.05964 \bar{\theta}^{4}$ \\
\hline
\end{tabular}

Here, $\bar{s}=\frac{x_{1} s_{1}+x_{2} s_{2}}{x_{1}+x_{2}}$, is the average quality in the market and $T W_{f h}\left(T W_{f l}\right)$ is domestic welfare ${ }^{13}$ when the foreign firm produces the high (low) quality good and the domestic firm the low (high) quality good. Note that under free trade, there are two asymmetric pure strategy equilibria. In one the domestic firm is the high quality producer and in the other it is the low quality producer. ${ }^{14}$ The domestic firm's profits, as well as domestic welfare, are higher in the equilibrium in which the domestic firm is the high quality producer.

\section{Tariffs: The ex-post and the ex-ante game}

Two alternative assumptions can be made regarding the timing of the policy decisions. First is the conventional assumption where the government chooses its level of policy instrument in the first stage of the game. Following Neary (1991) we refer to this case as the ex-ante game. In this game the government acts as a Stackelberg leader towards the firms setting the level of its policy instrument. Taking the government policy as given, the domestic and the foreign firm then act as Stackelberg followers and first choose their level of quality and then subsequently make their output decisions. Second, the government chooses its policy level before the market competition stage and after the firms have made their quality choices. Again, following Neary (1991), we refer to this case as the ex-post game. Firms now act as Stackelberg leaders in their quality decisions. The government takes the firms' quality choices as given when it decides on its policy level.

A time consistency problem arises in the ex-ante game. Given that the government announces its policy level before the firms make their quality choices, the policy may be rendered suboptimal ex-post. Therefore, unless it possesses a

\footnotetext{
${ }^{13}$ Domestic welfare is defined as the (unweighted) sum of the domestic firm's profits and consumer surplus. The latter consists of the net surplus of consumers purchasing the high, and the low, quality good and is given by, $C S=s_{1}\left[\bar{\theta}^{2}-\left(\theta-x_{1}\right)^{2}\right]-p_{1} x_{1}+s_{2}\left[\left(\theta-x_{1}\right)^{2}-\left(\theta-x_{1}-x_{2}\right)^{2}\right]-p_{2} x_{2}$.

${ }^{14}$ There is also a symmetric equilibrium in mixed strategies where each firm chooses with some positive probability the higher quality good and otherwise chooses the lower quality good. In line with all the existing literature on vertical product differentiation, we abstain from the analysis of mixed strategy equilibria (see e.g. Tirole, 1989; Motta, 1993; Shaked and Sutton, 1982, 1983, 1984; Sutton, 1991).
} 
specific commitment mechanism, the government has an incentive to modify its trade policy after the firms have incurred their sunk costs of quality. Policy announcements in this scenario can be justified only if the domestic government can credibly commit to a level of the policy instrument.

The time consistency problem, however, does not arise in the ex-post game. The firms correctly anticipate the ex-post optimal policy and choose their quality levels accordingly. Contrary to the ex-ante game, here the firms act as Stackelberg leaders making their quality choices strategically to influence the government's choice of the policy instrument level in the subsequent stage.

In this paper, we consider that the government's policy instrument is a tariff on imports. We compare the outcomes of the ex-ante and the ex-post games with the benchmark free trade case. The solution concept employed to solve for the multi-stage game is subgame perfect equilibrium.

\subsection{Ex-post tariffs}

In this section we analyze the ex-post tariff game and compare its equilibrium outcome with free trade. As mentioned above, there are two equilibria under free trade: (i) the foreign firm producing high quality and the domestic firm producing low quality, and (ii) vice versa.

Interestingly, in the ex-post tariff game, the foreign firm never produces the high quality good in equilibrium. In the unique equilibrium of this game, the domestic firm is always high quality. This occurs because a foreign firm (producing high quality under free trade), anticipating the optimal import tariff in the ex-post game, will switch positions in the quality ladder and instead produce the low quality good. The reason is quite simple. The foreign firm switches position in the quality ladder because it knows that under ex-post tariffs the government has a second mover advantage. If the foreign firm selects a high level of quality (incurring high sunk costs), the government, exploiting its second mover advantage, sets a high tariff thus expropriating the gross profits of the foreign firm. This would then result in negative net profits for the (high quality) foreign firm.

Below we analyze the two cases in which the foreign firm produces the high or the low quality good. We show that the foreign firm achieves positive (net) profits only as a low quality producer.

\subsubsection{High quality foreign firm}

Let $\bar{t}$ be the per-unit output tariff imposed on the high quality foreign firm. For analytical convenience, define $t=\frac{\bar{t}}{\theta}$. Then the profits of the foreign and the domestic firm are $\pi_{1}=p_{1}\left(x_{1}, x_{2}\right) x_{1}{ }^{\theta} \cdot \bar{t} \bar{\theta} x_{1}-\frac{s_{1}^{2}}{2}$ and $\pi_{2}=p_{2}\left(x_{1}, x_{2}\right) x_{2}-\frac{s_{2}^{2}}{2}$, respectively. Solving for the last stage, each firm chooses its output to maximize profits taking the output of its rival as given. From the first order conditions we obtain the best response functions: 


$$
x_{1}=\frac{\bar{\theta} s_{1}-s_{2} x_{2}-\bar{\theta} t}{2 s_{1}} ; \quad x_{2}=\frac{\bar{\theta}-x_{1}}{2}
$$

It is easy to see from the reaction functions that the tariff increases the marginal cost of the foreign firm. The tariff shifts the reaction function of the foreign firm downward resulting in a decrease in the market share of the foreign firm and an increase in market share of the domestic firm. ${ }^{15}$ From (5) the equilibrium outputs are:

$$
x_{1}^{*}\left(t, s_{1}, s_{2}\right)=\left[\frac{2 s_{1}-s_{2}-2 t}{4 s_{1}-s_{2}}\right] \bar{\theta} ; \quad x_{2}^{*}\left(t, s_{1}, s_{2}\right)=\left[\frac{s_{1}+t}{4 s_{1}-s_{2}}\right] \bar{\theta}
$$

Then the equilibrium profits are $\pi_{i}^{*}\left(t, s_{1}, s_{2}\right)=s_{i} x_{i}^{*^{2}}-\frac{s_{i}^{2}}{2}, i=1,2$.

Given the quality choices of the foreign and the domestic firm, the domestic government selects the ex-post tariff level that maximizes domestic welfare. Domestic welfare is the sum of consumer surplus, the domestic firm's profits and tariff revenues $\left(\bar{t} \bar{\theta} x_{1}^{*}\right)$. From (6) and (3), and manipulating, we get:

$$
T W\left(t, s_{1}, s_{2}\right)=\left[\frac{s_{1}^{2}+s_{1} s_{2}+2 s_{1} t-3 t^{2}}{2\left(4 s_{1}-s_{2}\right)}\right] \bar{\theta}^{2}-\frac{s_{2}^{2}}{2}
$$

From the first order condition we obtain the optimal import tariff, $\bar{t}^{*}=\frac{s_{1}}{3} \bar{\theta}$. The optimal ex-post tariff is proportional to the foreign firm's quality level and increases with the size of the market, $\bar{\theta}$. The higher the quality the foreign firm chooses in the first stage, the higher the import tariff will be and the lower will be, thus, its market share and profits. In fact, whenever the domestic firm is the low quality producer, the profits of the foreign firm are always negative independent of the quality level selected by the domestic firm in the first stage. The foreign firm thus has no incentive to produce the high quality good. These results are summarized in the following.

Proposition 1. A foreign firm, anticipating the ex-post optimal tariff $\bar{t}^{*}=\frac{s_{1}}{3} \bar{\theta}$, never produces the high quality good.

Proof. Let the domestic and the foreign firm select quality in the first stage anticipating that the government's ex-post optimal tariff will be $\bar{t}^{*}=\frac{s_{1}}{3} \bar{\theta}$. Then, from (6), we obtain the firms' outputs as functions of their qualities:

$$
x_{1}^{*}\left(s_{1}, s_{2}\right)=\frac{4 s_{1}-3 s_{2}}{3\left(4 s_{1}-s_{2}\right)} \bar{\theta} ; \quad x_{2}^{*}\left(s_{1}, s_{2}\right)=\frac{4 s_{1}}{3\left(4 s_{1}-s_{2}\right)} \bar{\theta}
$$

where their profits are $\pi_{i}^{*}\left(s_{1}, s_{2}\right)=s_{i} x_{i}^{*^{2}}-\frac{s_{i}^{2}}{2}, i=1,2$. Given the quality level of

\footnotetext{
${ }^{15}$ This is the market share effect in Brander and Spencer (1985).
} 
its rival each firm chooses its quality to maximize profits. The first order conditions can then be written as:

$$
s_{1}(\lambda)=\left[\frac{(4-3 \lambda)\left(16+3 \lambda^{2}\right)}{9(4-\lambda)^{3}}\right] \bar{\theta}^{2} ; \quad s_{2}(\lambda)=\left[\frac{16(4+\lambda)}{9(4-\lambda)^{3}}\right] \bar{\theta}^{2}
$$

with $\lambda=s_{2} / s_{1}$. To show that the foreign firm never produces the high quality good, it is sufficient to show that its profits, $\pi_{1}\left(s_{1}, s_{2}\right)$, are always negative. First, it

can be checked that the domestic firm never chooses a quality level $s_{2}<0.111 \bar{\theta}^{2}$. From the first order condition of the domestic firm we observe that the optimal quality for the domestic firm is always larger than $0.111 \bar{\theta}^{2}$ (the minimum attained at $\lambda=0$, i.e. $\left.s_{1}=+\infty\right)$. Further, it can be checked that $\max _{s_{1}} \pi_{1}\left(s_{1}, s_{2}\right)<0$ for all $s_{2}>0.0568149 \bar{\theta}^{2}$. Therefore, the foreign firm's profits are always negative whenever the (low quality) domestic firm sets its quality level optimally. Thus the foreign firm never chooses to be the high quality producer under ex-post import tariffs. Q.E.D

\subsubsection{Low quality foreign firm}

The analysis is similar to the case in which the foreign firm is of high quality. The domestic and the foreign firms' profits are $\pi_{1}=p_{1}\left(x_{1}, x_{2}\right) x_{1}-\frac{s_{1}^{2}}{2}$ and $\pi_{2}=$ $p_{2}\left(x_{1}, x_{2}\right) x_{2}-\bar{t} \bar{\theta} x_{2}-\frac{s_{2}^{2}}{2}$, respectively. In the final stage firms simultaneously choose their outputs. From the focs we obtain the best response functions:

$$
x_{1}=\frac{\bar{\theta} s_{1}-x_{2} s_{2}}{2 s_{1}} ; \quad x_{2}=\frac{\bar{\theta} s_{2}-x_{1} s_{2}-\bar{t} \bar{\theta}}{2 s_{2}}
$$

Then the equilibrium outputs are:

$$
x_{1}^{*}\left(t, s_{1}, s_{2}\right)=\left[\frac{2 s_{1}-s_{2}+t}{4 s_{1}-s_{2}}\right] \bar{\theta} ; \quad x_{2}^{*}\left(t, s_{1}, s_{2}\right)=\left[\frac{s_{1}\left(s_{2}-2 t\right)}{s_{2}\left(4 s_{1}-s_{2}\right)}\right] \bar{\theta}
$$

and the equilibrium profits are $\pi_{i}^{*}\left(t, s_{1}, s_{2}\right)=s_{i} x_{i}^{*^{2}}-\frac{s_{i}^{2}}{2}, i=1,2$. The government selects a tariff in the second stage to maximize domestic welfare, which from (10) and (3) can be written as:

$$
T W\left(t, s_{1}, s_{2}\right)=\left[\frac{3 s_{1}^{2} s_{2}-s_{1} s_{2}^{2}+2 s_{1} s_{2} t-3 s_{1} t^{2}}{2 s_{2}\left(4 s_{1}-s_{2}\right)}\right] \bar{\theta}^{2}-\frac{s_{1}^{2}}{2}
$$

From the first order condition we derive the optimal tariff for the government, $\bar{t}^{*}=\left(\frac{s_{2}}{3}\right) \bar{\theta}$. Note that as before the optimal tariff is proportional to the foreign firm's quality level and the size of the market. The optimal ex-post tariff creates a disincentive for the foreign firm to invest in quality in the first stage and thus, as is shown below, its quality level is lower than under free trade. In the first stage, the 
firms simultaneously select quality level anticipating that the government will choose an import tariff $\bar{t}^{*}=s_{2} / 3 \bar{\theta}$. From (10) we get:

$$
x_{1}^{*}\left(s_{1}, s_{2}\right)=\frac{2\left(3 s_{1}-s_{2}\right)}{3\left(4 s_{1}-s_{2}\right)} \bar{\theta} ; \quad x_{2}^{*}\left(s_{1}, s_{2}\right)=\frac{s_{1}}{3\left(4 s_{1}-s_{2}\right)} \bar{\theta}
$$

and $\pi_{i}^{*}\left(s_{1}, s_{2}\right)=s_{i} x_{i}^{*^{2}}-\frac{s_{i}^{2}}{2}$. Then the first order conditions can be written as:

$$
s_{1}(\lambda)=\frac{4(3-\lambda)\left(12-5 \lambda+\lambda^{2}\right)}{9(4-\lambda)^{3}} \bar{\theta}^{2} ; \quad s_{2}(\lambda)=\frac{(4+\lambda)}{9(4-\lambda)^{3}} \bar{\theta}^{2}
$$

with $\lambda=s_{2} / s_{1}$. Dividing $s_{2}(\lambda)$ with $s_{1}(\lambda)$ and solving for $\lambda$ we obtain $\lambda^{*}=$ $0.028584 .{ }^{16}$ Then from (13), (12) and (11) we obtain the equilibrium qualities, quantities, profits, the optimal ex-post tariff and domestic welfare (note that $H$ denotes the domestic firm and $F$ the foreign firm):

\begin{tabular}{lll}
\hline$s_{1}^{H *}=0.25001 \bar{\theta}^{2}$ & $s_{2}^{F *}=0.00715 \bar{\theta}^{2}$ & $\bar{s}^{*}=0.215 \bar{\theta}^{2}$ \\
\hline$x_{1}^{H *}=0.4988 \bar{\theta}$ & $x_{2}^{F *}=0.08393 \bar{\theta}$ & $t^{*}=0.00238 \bar{\theta}^{2}$ \\
\hline$\pi_{1}^{H *}=0.03095 \bar{\theta}^{4}$ & $\pi_{2}^{F *}=0.00002 \bar{\theta}^{4}$ & $C S^{*}=0.03143 \bar{\theta}^{4}$ \\
& & $T W^{*}=0.06258 \bar{\theta}^{4}$
\end{tabular}

Proposition 2 summarizes the results obtained under ex-post tariffs.

Proposition 2. Under ex-post optimal import tariffs, there is a unique equilibrium in which the foreign firm is always the low quality producer. Under ex-post tariffs the qualities offered by both the firms are lower than the equilibrium qualities under free trade. However, average quality and domestic welfare are always higher under ex-post tariffs than under free trade.

While the profits of the foreign firm are negative whenever it produces the high quality good, they are positive if it produces the low quality good. The foreign firm, knowing that the higher its quality level, the higher the optimal import tariff will be, strategically selects a lower quality in the first stage in order to induce a lower tariff level from the government in the subsequent stage. A foreign firm (producing the high quality good under free trade), anticipating the ex-post optimal tariff $\bar{t}^{*}=\left(s_{F} / 3\right) \theta$ (where $s_{F}$ is its own quality), will switch position in the quality ladder and instead produce the low quality good. Contrarily, a low quality foreign

\footnotetext{
${ }^{16}$ This is the unique real root of the equation that is smaller than one.
} 
firm keeps producing the low quality good after the imposition of the ex-post optimal tariff.

Quality switching is observed as the government chooses its tariff level after the foreign firm has invested in its quality. Since the foreign firm's gross profits are higher when it produces the high quality good, the government can raise more revenues by imposing a higher tariff on the (high quality) foreign firm. Under the optimal ex-post tariff both the high and the low quality offered in the market are lower than under free trade. The foreign firm, faced with the import tariff, offers a lower quality (relative to free trade) in order to save on costs of quality and thus obtain positive profits. As product differentiation increases, the domestic firm also saves on quality costs by offering a lower quality (relative to free trade). Despite the drop in what each firm offers, the average quality increases as the tariff shifts the market share from the low quality foreign firm to the high quality domestic firm. Nevertheless, the reduction in total output due to the imposition of the tariff outweighs the positive effect of the increase in average quality. As a result consumer surplus is lower than under free trade.

Domestic welfare is higher under ex-post tariffs than under free trade. ${ }^{17}$ The reason is that the introduction of an ex-post tariff shifts profits to the domestic firm and tariff revenues to the domestic government. The welfare increase is substantially stronger when the tariff induces a quality reversal due to a big increase in the domestic firm's profits. Our finding is in line with the Grossman (1988) critique that the long run view of the rent shifting effect may be different than the short run view given in Brander and Spencer (1985). In fact in our long run scenario where firms first choose quality and then compete in the market, the rent shifting effect is reinforced due to the reversal in the equilibrium quality configuration induced by the ex-post tariff. With the ex-post tariff the domestic firm always produces the high quality good and hence the rent transfer effect is of a higher order of magnitude than the classic Brander and Spencer rent shifting effect.

\subsection{Ex-ante tariffs}

Consider now the case where the government commits to an import tariff level before the firms (choosing simultaneously) first select their qualities and then their outputs. Two possibilities arise in this case. The government can either set a non-prohibitive tariff that leaves a duopoly in the market, or it could set a prohibitive tariff ${ }^{18}$ that would result in a domestic monopoly.

Interestingly, the optimal ex-ante tariff is the prohibitive tariff. The resulting domestic monopolist increases domestic welfare over free trade due to an increase

\footnotetext{
${ }^{17}$ Note, and as is seen below, under Bertrand competition domestic welfare increases only if the foreign firm produces the high quality good under free trade.

${ }^{18}$ The possibility of governments resorting to prohibitive tariffs was suggested by the Editor, Jonathan Eaton.
} 
in its profits. The average quality increases and consumer surplus decreases relative to free trade. The prohibitive tariff gives greater domestic welfare than any non-prohibitive ex-ante tariff independent of whether the domestic firm produces the high, or the low, quality good. In fact, the optimal non-prohibitive tariff is the one that leaves the foreign firm indifferent between staying in, or exiting, the market (i.e. it makes zero profits in equilibrium).

Unlike the ex-ante tariff, under an ex-post tariff a government can expropriate the gross profits of the foreign firm by setting its tariff level after the firms have incurred their sunk costs of quality. The optimal ex-post tariff is not prohibitive and leaves room for the foreign firm to sell a small quantity of the low quality good at positive profits. Hence, output and consumer surplus are higher than under the ex-ante prohibitive tariff. Further, under ex-post tariffs the government earns positive tariff revenues from foreign sales that partially compensate for the decrease in the domestic firm's profits (that are lower due to foreign competition). Consequently, domestic welfare is higher under ex-post tariffs. ${ }^{19}$

This result is in contrast to what has been shown for output subsidies where government commitment increases welfare. In our model the government has at its disposal only one instrument to achieve three targets: to shift rents to the domestic firm and to correct for output and quality investment distortions due to the firms' market power. The government has a second mover advantage in the ex-post game and achieves greater welfare by setting the tariff level after the firms have incurred the sunk costs of quality.

Below, we first analyze the domestic monopoly resulting from an ex-ante prohibitive tariff. We then show that domestic welfare is higher under a prohibitive tariff than under any non-prohibitive tariff.

\subsubsection{The prohibitive tariff}

Under a prohibitive tariff the domestic monopoly offers a single quality of the good. The consumer who is indifferent between buying and not buying the good has the taste parameter $\theta_{M}=p_{M} / s_{M}$ (the subscript $M$ stands for the domestic monopolist case). All the consumers with $\bar{\theta}<\theta<\theta_{M}$ purchase the good with quality $s_{M}$. The monopolist thus faces the demand curve:

$$
x\left(p_{M}, s_{M}\right)=\bar{\theta}-\frac{p_{M}}{s_{M}}
$$

and its profits are $\pi_{M}=s_{M}\left(\bar{\theta}-x_{M}\right) x_{\underline{M}}-\frac{s_{M}^{2}}{2}$. Maximizing with respect to $s_{M}$ and $x_{M}$,we obtain $x_{M}^{*}=0.5 \bar{\theta}$ and $s_{M}^{*}=0.25 \theta^{2}$. Then the equilibrium outcome under the ex ante prohibitive tariff is:

\footnotetext{
${ }^{19}$ Note, as pointed out by the Editor, a government can make a tariff contingent on the quality ex-post. In this case, the government can always do ex-ante at least what it can do ex-post. However, in this paper we look only at government announcement of levels of a tariff.
} 
$s_{M}^{*}=0.25 \bar{\theta}^{2}$

$x_{M}^{*}=0.5 \bar{\theta} \quad \pi_{M}^{*}=0.03125 \bar{\theta}^{4}$

$C S_{M}^{*}=0.03125 \bar{\theta}^{4} \quad T W_{M}^{*}=0.0625 \bar{\theta}^{4}$

The domestic monopolist serves half the market and offers a quality level that is (slightly) lower than the high quality produced under both free trade $\left(s_{1}^{F T}=\right.$ $\left.0.25194 \bar{\theta}^{2}\right)$ and ex-post tariffs $\left(s_{1}^{H} *=0.25001 \bar{\theta}^{2}\right)$. Hence, the total output sold in the market is substantially lower than under free trade $\left(x_{M}^{*}=0.5 \bar{\theta}<x_{1}^{F T}+x_{2}^{F T}=\right.$ $0.7254 \bar{\theta})$, or under ex-post tariffs $\left(x_{M}^{*}=0.5 \bar{\theta}<x_{1}^{H *}+x_{2}^{F *}=0.58273 \bar{\theta}\right)$. The smaller number of consumers served under a prohibitive tariff results in lower consumer surplus. However, the increase in the domestic firm's profits due to the prohibitive tariff more than compensates for the decrease in consumer surplus. As a result, domestic welfare under a domestic monopolist is greater than under free trade, independently of whether free trade imports are of high, or low, quality. In contrast, due to zero tariff revenues, substantially lower output, and only slightly higher profits for the domestic firm, domestic welfare under the ex-ante prohibitive tariff is lower than under the optimal ex-post tariff.

\subsubsection{The non-prohibitive optimal tariff}

To complete our analysis, we also consider non-prohibitive ex-ante tariffs. We show that the government imposes the maximum tariff that still leaves a duopoly in the market. Under the maximum non-prohibitive tariff the foreign firm makes zero profits. Independent of whether the foreign firm is high, or low, quality, domestic welfare under this tariff is lower than under the prohibitive tariff. Below we briefly present the analysis for the ex-ante non-prohibitive tariffs. We consider the case where the foreign firm is the high, or low, quality producer. ${ }^{20}$

\subsubsection{High quality foreign firm}

The last stage is the same as in the ex-post game and the equilibrium outputs are given by (6). In the second stage, firms choose quality levels simultaneously to maximize profits, $\pi_{i}^{*}\left(t, s_{1}, s_{2}\right)=s_{i} x_{i}^{*^{2}}-\frac{s_{i}^{2}}{2}, i=1,2$. Defining $\lambda=s_{2} / s_{1}$ and $\mu=t /$ $s_{1}$, from (6) the focs for the domestic and the foreign firm are, respectively:

$$
s_{1}(\lambda, \mu)=\left[\frac{(2-\lambda-2 \mu)\left(8-2 \lambda+\lambda^{2}+8 \mu+2 \lambda \mu\right)}{(4-\lambda)^{3}}\right] \bar{\theta}^{2}
$$

\footnotetext{
${ }^{20} \mathrm{~A}$ more detailed treatment of non-prohibitive tariffs is given in Herguera et al. (1997).
} 


$$
s_{2}(\lambda, \mu)=\left[\frac{(4+\lambda)(1+\mu)^{2}}{(4-\lambda)^{3}}\right] \bar{\theta}^{2}
$$

Since Eqs. (14) and (15) cannot be solved analytically for $\lambda$ and $\mu$, we proceed as follows. Dividing (14) and (15), we obtain an equation involving only $\lambda$ and $\mu$. ${ }^{21}$ Solving for $\mu$ and choosing the positive $\operatorname{root}^{22}$ we get $\mu(\lambda)$. To plot $\mu(\lambda)$ we need first to determine the relevant range for the quality ratio $\lambda$. Note that for $t=0$ (free trade), $\lambda_{0}=s_{2}^{F T} / s_{1}^{F T}=0.35811$. On the other hand, there is a maximum tariff $t_{m}$ for which the foreign firm still stays in the market, making zero profits. To determine $t_{m}$ and its respective qualities $\left(s_{1 m}, s_{2 m}\right)$, we solve the system of focs (14) and (15) together with the zero-profit condition for the foreign firm. We thus obtain the maximum tariff $t_{m}=0.02765 \bar{\theta}^{2}$ and the respective ratio of qualities $\lambda_{m}=s_{2 m} / s_{1 m}=0.57538$. Hence, the relevant range of $\lambda$ is [0.35811, 0.57538]. ${ }^{23}$ Plotting $\mu(\lambda)$ in this range, we see that $\mathrm{d} \mu / \mathrm{d} \lambda>0$. Further, substituting $\mu(\lambda)$ in (14) and (15) we obtain $s_{1}(\lambda)$ and $s_{2}(\lambda){ }^{24}$ By plotting these expressions, it is seen that $s_{2}(\lambda)$ is increasing and $s_{1}(\lambda)$ is decreasing with $\lambda$. Moreover, by plotting $t(\lambda)=s_{1}(\lambda) \cdot \mu(\lambda)$ we see that $\mathrm{d} \lambda / \mathrm{d} t>0$ for all $\lambda$ in the relevant range.

Therefore, as the tariff on the imports increases, the foreign firm decreases and the domestic firm increases its quality level (see Fig. 1). Further, substituting $s_{i}(\lambda)$, $i=1,2$ and $t(\lambda)$ in (6) and plotting in the relevant range, we see that with an increase in the tariff the profits of the foreign (domestic) firm decrease (increase) with the level of the tariff. Second, consumer surplus initially decreases and then increases with the tariff and reaches its maximum under free trade. Third, domestic welfare increases with the import tariff (Fig. 2). Hence, the welfare maximizing non-prohibitive tariff is $\tilde{t}=t_{m}=0.02765 \bar{\theta}^{2}$. The equilibrium outcome is:

\begin{tabular}{lll}
\hline$\tilde{s}_{1}^{F}=0.24517 \bar{\theta}^{2}$ & $\tilde{s}_{2}^{H}=0.14107 \bar{\theta}^{2}$ & $\tilde{\bar{s}}=0.19506 \bar{\theta}^{2}$ \\
\hline$\tilde{x}_{1}^{F}=0.35013 \bar{\theta}$ & $\tilde{x}_{2}^{H}=0.32494 \bar{\theta}$ & $\tilde{t}=0.02765 \bar{\theta}^{2}$ \\
\hline$\tilde{\pi}_{1}^{F}=0$ & $\tilde{\pi}_{2}^{H}=0.00494 \bar{\theta}^{4}$ & $\widetilde{C S}=0.03852 \bar{\theta}^{4}$ \\
& & $T W=0.05315 \bar{\theta}^{4}$ \\
\hline
\end{tabular}

Since domestic welfare under the optimal non-prohibitive ex-ante tariff is lower than under the prohibitive tariff $\left(T W<T W_{M}^{*}=0.0625 \bar{\theta}^{4}\right)$, the government will

\footnotetext{
${ }^{21}$ This is an equation which is quadratic in $\mu$, i.e $\left(4+17 \lambda+4 \lambda^{2}\right) \mu^{2}+\left(8+2 \lambda+4 \lambda^{3}\right) \mu=15 \lambda-$ $12 \lambda^{2}+4 \lambda^{3}-\lambda^{4}-4$.

${ }^{22}$ Since $s_{1}, s_{2}$ and $t$ are positive, $\mu$ and $\lambda$ are also positive, the positive root is the relevant root of the equation.

${ }^{23}$ This is so, because the ratio of qualities is strictly increasing in the tariff level (see below).

${ }^{24}$ The analytical expressions of $\mu(\lambda), s_{i}(\lambda), t(\lambda)$ etc. are available from the authors upon request.
} 


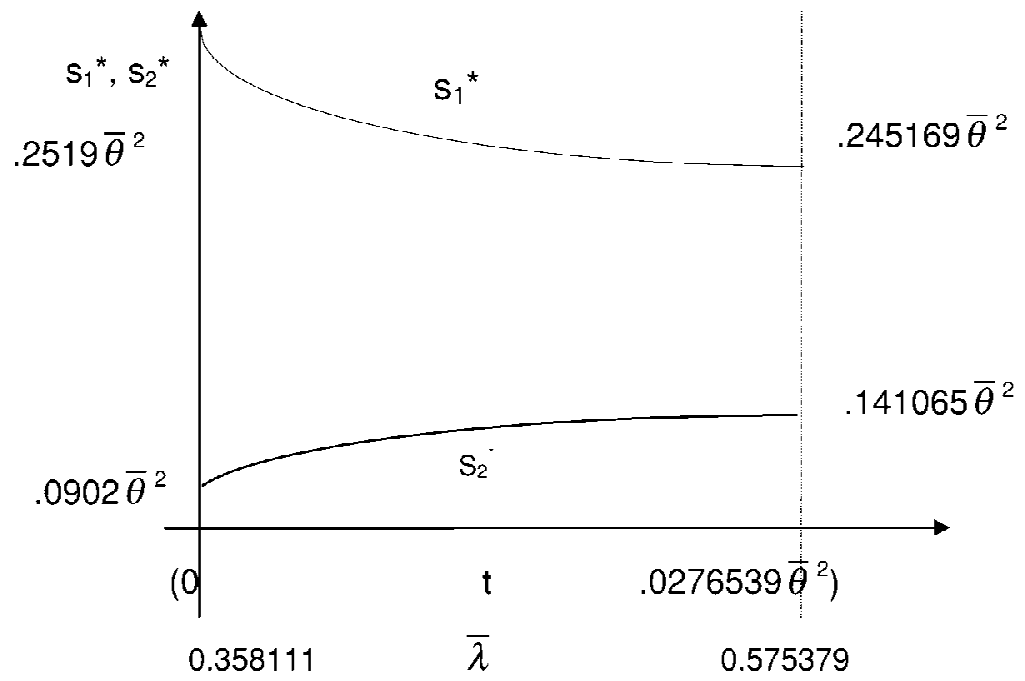

Fig. 1. Foreign high quality: Quality choice and tariffs.

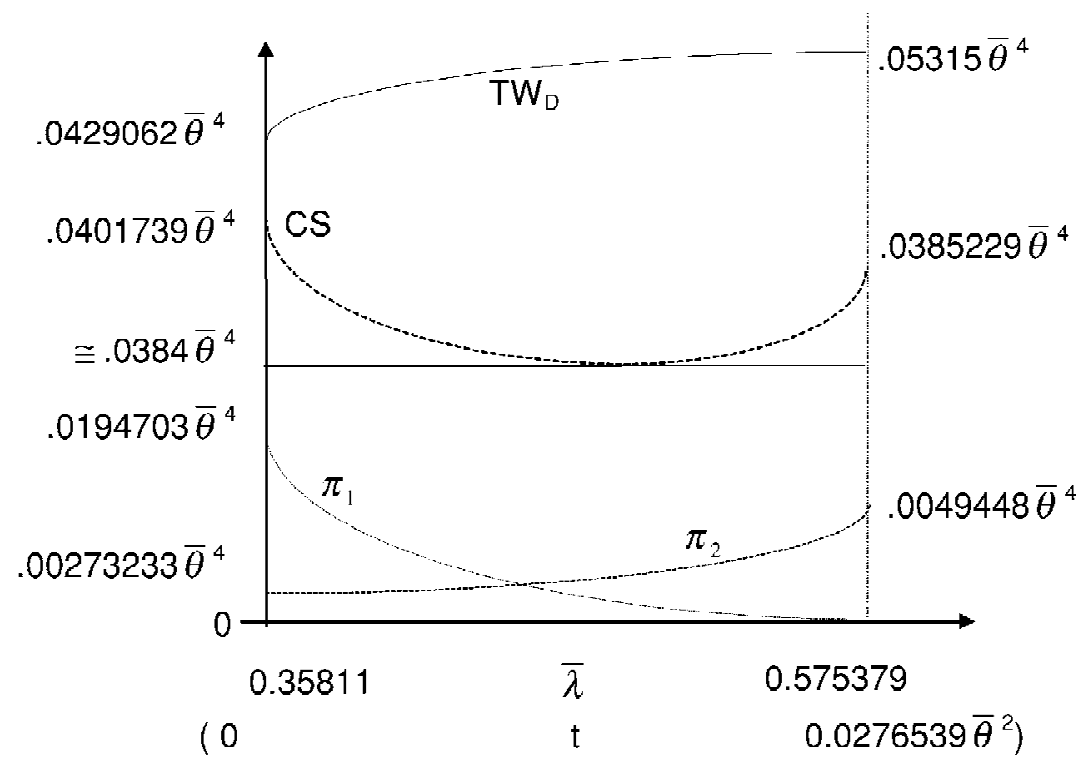

Fig. 2. Foreign high quality: Total welfare, consumer surplus and profits. 
optimally set a prohibitive tariff in the ex-ante game. The reason is as follows. Under a non-prohibitive tariff, domestic production is low quality and the domestic firm's profits are substantially lower than when the domestic firm is a monopolist selling the single (high) quality good. The tariff revenues and the increase in consumer surplus (resulting from the non-prohibitive tariff) do not compensate for the decrease in the domestic firm's profit. Thus, domestic welfare is higher under the prohibitive ex-ante tariff.

\subsubsection{Low quality foreign firm}

Following similar steps as above, we determine the foreign and domestic firms' quality in the second stage as functions of the level of tariff imposed on the low quality foreign firm. Defining $\hat{\lambda}=1 / \lambda=s_{1} / s_{2}$ and $\hat{\mu}=1 / \mu=t / s_{2}$ and using the outcome of the last stage of the game (given by (10)), the focs for the domestic and the foreign firm, respectively, are: ${ }^{25}$

$$
\begin{aligned}
& s_{1}(\hat{\lambda}, \hat{\mu})=\frac{(2 \hat{\lambda}-1+\hat{\mu})\left(8 \hat{\lambda}^{2}-2 \hat{\lambda}+1-4 \hat{\lambda} \hat{\mu}-\hat{\mu}\right)}{(4 \hat{\lambda}-1)^{3}} \\
& s_{2}(\hat{\lambda}, \hat{\mu})=\frac{\hat{\lambda}^{2}(1-2 \hat{\mu})(4 \hat{\lambda}+1+8 \hat{\lambda} \hat{\mu}-6 \hat{\mu})}{(4 \hat{\lambda}-1)^{3}}
\end{aligned}
$$

The above equations together with the zero profit condition for the foreign firm determine the maximum tariff, $\hat{t}_{m}=0.01064 \bar{\theta}^{2}$ and the associated ratio of qualities, $\hat{\lambda}_{m}=3.513$. Hence, the relevant range of ex-ante non-prohibitive tariffs is $t \in\left[0,0.01064 \bar{\theta}^{2}\right]$ and the associated interval of quality ratios is $\hat{\lambda} \in[2.79243$, 3.513].

Figs. 3 and 4 summarize our findings. First, both firms lower their quality level as the import tariff increases. Second, the foreign (domestic) firm's profits decrease (increase) with the level of the tariff. Third, consumer surplus decreases, while domestic welfare increases, with the tariff level.

The government thus optimally sets the maximum ex-ante tariff, $\tilde{t}=\hat{t}_{m}=$ $0.01064 \theta^{2}$. Then the equilibrium outcome is:

\begin{tabular}{lll}
\hline$\tilde{s}_{1}^{H}=0.25123 \bar{\theta}^{2}$ & $\tilde{s}_{2}^{F}=0.07151 \bar{\theta}^{2}$ & $\tilde{s}=0.19991 \bar{\theta}^{2}$ \\
\hline$\tilde{x}_{1}^{H}=0.4731 \bar{\theta}$ & $\tilde{x}_{2}^{F}=0.18906 \bar{\theta}$ & $\tilde{t}=0.01064 \bar{\theta}^{2}$ \\
\hline$\tilde{\pi}_{1}^{H}=0.02467 \bar{\theta}^{4}$ & $\tilde{\pi}_{2}^{F}=0$ & $\widetilde{C S}=0.03579 \bar{\theta}^{4}$ \\
\hline
\end{tabular}

\footnotetext{
${ }^{25}$ The expressions for $\hat{\mu}(\hat{\lambda}), s_{i}(\hat{\lambda})$ and $t(\hat{\lambda})$ etc. are available from the authors upon request. Note that $\mathrm{d} \hat{\lambda} / \mathrm{d} t>0$ for $\lambda$ in the range [2.79243, 3.513].
} 


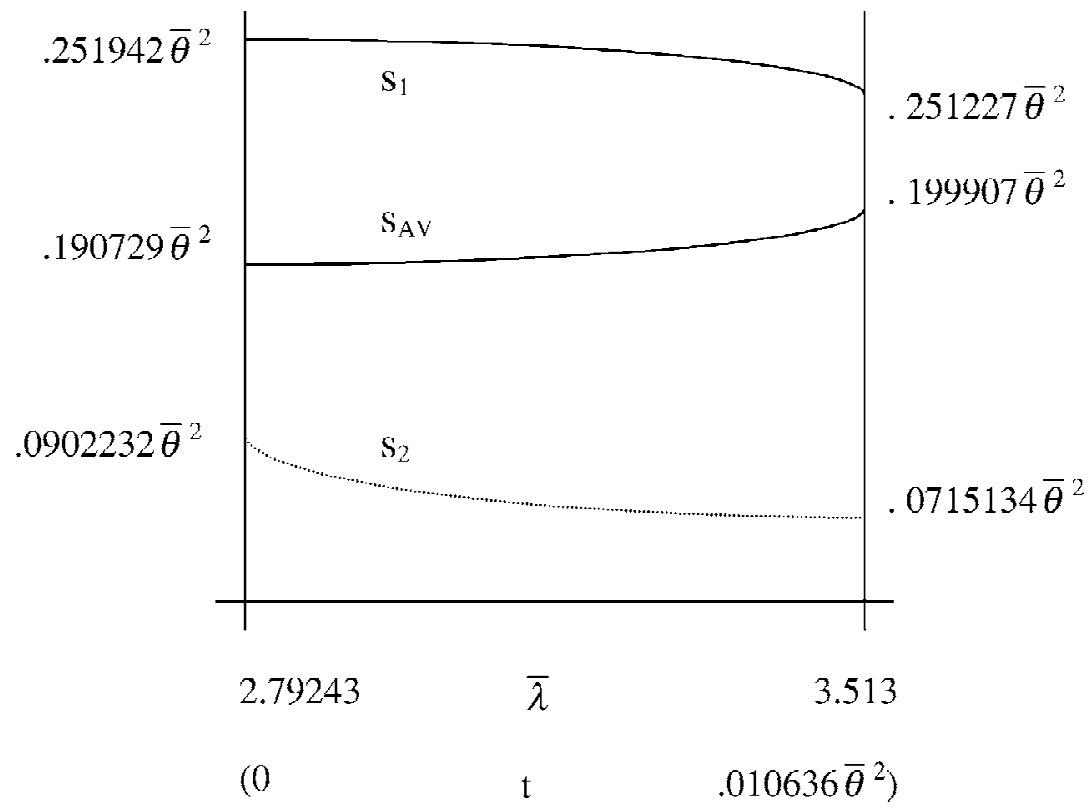

Fig. 3. Foreign low quality: Quality choice and tariffs.

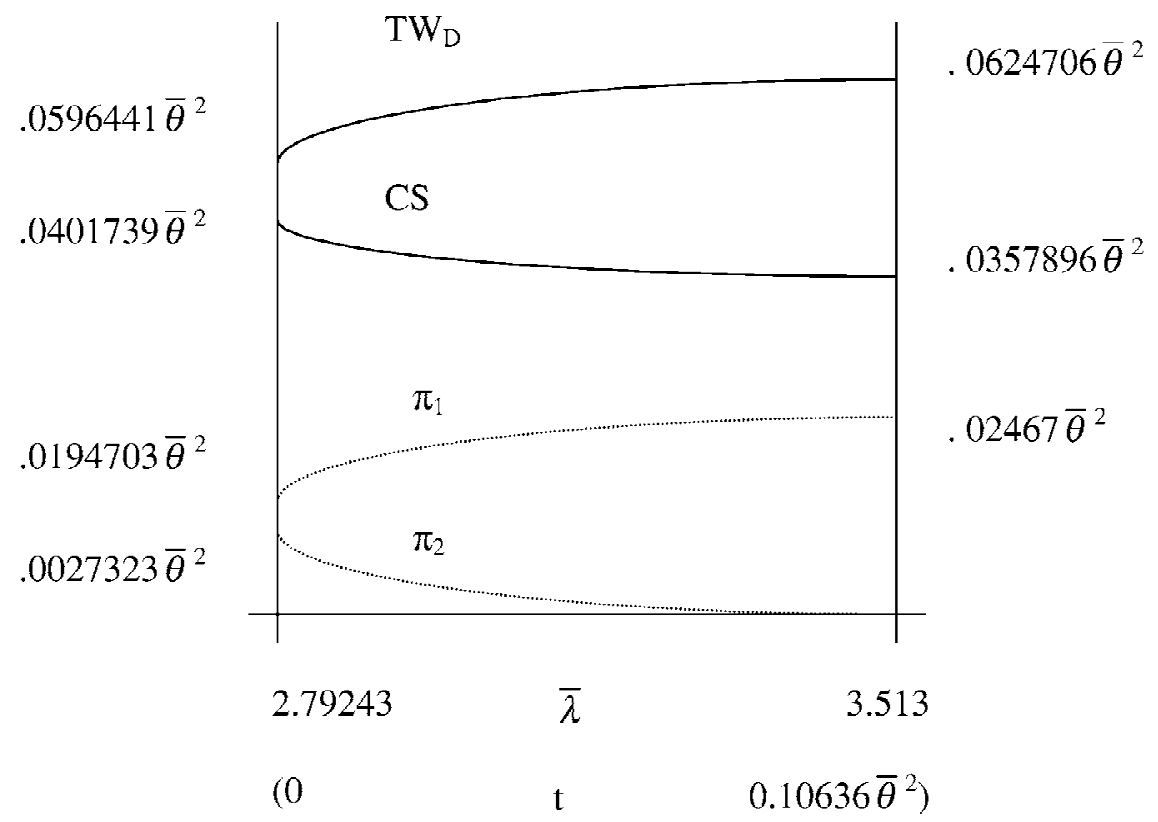

Fig. 4. Foreign low quality: Total welfare, consumer surplus and profits. 
In this case too domestic welfare is lower than under the prohibitive tariff $\left(\widetilde{T W}<T W_{M}^{*}=0.0625 \bar{\theta}^{4}\right)$, and hence the government (again) chooses a prohibitive tariff in the ex-ante game. The reason is as follows. Since the non-prohibitive tariff allows for low quality imports, the domestic firm's profits are lower than under a prohibitive tariff. The increase in consumer surplus (due to higher output) and the the tariff revenues from the imports, do not compensate for the reduction in the domestic firm's profits. As a result, domestic welfare is higher under ex-ante prohibitive tariffs.

The above results are summarized in the following Proposition:

Proposition 3. The optimal ex-ante tariff is always the prohibitive tariff. The domestic monopolist sells less than the total output sold under the ex-post optimal tariff. This results in lower consumer surplus and domestic welfare than under ex-post tariffs.

\section{Bertrand competition}

Our qualitative results do not change under price competition. As in quantity competition, there is a unique equilibrium under ex-post optimal tariffs, where the domestic firm always produces the high quality good. Comparing with free trade, quality reversal is observed under ex-post tariffs whenever imports are of high quality under free trade.

The underlying reason for quality reversal under Bertrand competition is somewhat different than under Cournot competition. Anticipating that the higher the quality level it chooses at the first stage, the higher the tariff on imports will be, a high quality foreign firm selects a substantially lower quality in order to save on quality costs. Given that the foreign firm's quality is not too high, the domestic firm can increase its profits by selecting a higher quality level than that of its rival, becoming thus the high quality producer. Similar to quantity competition, under ex-post optimal tariffs a market structure with a high quality foreign firm and a low quality domestic firm is not sustainable in equilibrium.

As under Cournot competition, equilibrium qualities under ex-post tariffs are lower than under free trade. Compared to free trade and ex-ante tariffs, domestic welfare is higher under ex-post tariffs (except for the case where the domestic firm is the high quality producer under free trade). The quality reversal substantially increases the domestic firm's profits thus increasing domestic welfare. This strong rent shifting effect dominates the two negative effects (fall in consumer surplus and tariff revenues) and is the reason behind the higher level of domestic welfare under the ex-post tariff. Nevertheless, the ex-ante optimal tariff is non-prohibitive and leads to higher domestic welfare whenever the domestic firm produces the high quality good. The rent shifting effect is not strong enough in this case and as a result the reduction in consumer surplus leads to lower domestic welfare under 
ex-post tariffs. This is contrary to what is observed under Cournot competition. The above results are summarized in the following proposition (see Appendix A for a proof).

Proposition 4. Under price competition, and ex-post tariffs, there is a unique equilibrium in which the domestic firm always produces the high quality good. The optimal ex-post tariff $\bar{t}^{*}=\frac{s_{f}\left(s_{1}-s_{2}\right)}{3 s_{1}-2 s_{2}} \bar{\theta}$ ( $s_{f}$ is the quality level of the foreign firm) induces a quality reversal whenever the foreign firm produces the high quality good under free trade. The quality offered by both the firms under ex-post tariffs is lower than under free trade. When the foreign firm is high (low) quality under free trade, domestic welfare is higher (lower) under ex-post optimal tariffs than under both the optimal ex-ante tariff and free trade.

\section{Conclusion}

Given that a significant portion of intra industry trade is characterized by different quality levels, the study of strategic trade policy in such industries is of major importance. In this paper we present some new results on the effect of ex-ante and ex-post tariffs in a vertically differentiated home market duopoly. We show that for most cases ex-post tariffs result in higher welfare than any ex-ante tariff. ${ }^{26}$ Under ex-post tariffs the domestic firm always produces the high quality good. Further, our qualitative results are robust to output and price competition.

Our results are important as they highlight the fact that ex-post optimal tariffs can be a welfare improving policy tool in a vertically differentiated industry. This is contrary to what has been observed in subsidy games, where ex-ante optimal subsidies are welfare improving. We obtain this result for two reasons. First, in our model the government commits to a specific tariff level and not to a tariff schedule (i.e., tariffs contingent on the quality of imports). Secondly, the government has at its disposal only one instrument to achieve three targets: shift rents to the domestic firm, and correct for the output and quality investment distortions due to the firms' market power. An ex-post tariff is more effective than an ex-ante tariff as the government chooses its policy level after the firms have borne their quality costs. Knowing that the higher its quality level in the first stage, the higher the ex-post tariff will be, the foreign firm invests less in quality and as a result faces a lower tariff. Due to the lower tariff and quality costs the foreign firm makes positive profits. Decreased investment in quality on the part of the foreign firm lowers the competitive pressure on the domestic firm which responds optimally by investing less in quality.

\footnotetext{
${ }^{26}$ Unless firms compete in prices and the domestic firm produces the high quality good.
} 
In our model, the long term view of the rent shifting effect (Grossman, 1988) is different than the short term view as given in Brander and Spencer (1985). The rent transfer effect due to a tariff in our model is often of a higher order of magnitude as quality configurations change under ex-post tariffs. In the presence of ex-post optimal tariffs the domestic firm always produces the high quality good and earns a much higher level of profits. An ex-post optimal tariff effectively transfers revenues from the foreign firm (high quality under free trade) to the domestic firm (high quality under ex-post tariffs). As a result, the effect on domestic welfare is more dramatic than under ex-ante tariffs.

In our model, tariffs affect both investment in quality and market structure in an important way. Under ex-post tariffs the domestic firm is always the high quality producer. The ex-post tariff results in quality switching when the domestic firm offers the low quality good under free trade. In the presence of the ex-post tariff both the foreign and domestic firms lower their quality investment. Except for the case in which firms compete in prices and the foreign firm is low quality, the optimal ex-ante tariff is prohibitive and is thus greater than the optimal ex-post tariff. The resulting monopolist sells a lower quality and output in the market. Comparing with ex-post tariffs consumer surplus and tariff revenues are lower under an ex-ante tariff.

There are a number of limitations in our analysis. First, we focus on import tariffs only and do not consider domestic output subsidies. In a related paper (Herguera et al., 1997) we confirm that ex-ante output subsidies are welfare improving in vertically differentiated industries too. We further show that if a government can commit to a policy instrument in the first stage, but not to its level (as in Hwang and Schulman, 1993), it prefers import tariffs over output subsidies. Second, we do not consider multiple instruments (as in Dixit, 1988 and Collie, 1991). Whether a government can attain the first best outcome with the use of multiple policy instruments, and if so what set of tools would be necessary to achieve this target, is a question for further investigation. Third, we do not study retaliation games between the foreign and domestic government.

\section{Acknowledgements}

The authors would like to thank Jim Markusen and the participants at the meetings in Aix-en-Provence, The International Conference in Industrial Organization (Carlos III), Bellatera (Barcelona), ASSET (Alicante), ETSG (Erasmus) and seminars at Bologna and Vigo universities. The paper was written when Herguera and Petrakis were at Carlos III. The authors would like to thank an anonymous referee, Berthold Herrendorf, and especially the Editor, Jonathan Eaton, for detailed comments that led to a complete rewrite of the paper. Kujal acknowledges support from grants DGESIC \#PB98/0024 and CAM 06/0058/2001. Herguera acknowledges support from grant \#PB93-236. All remaining errors are our own. 


\section{Appendix A. Proof of Proposition 4}

Under free trade, in the last stage firm $i$ chooses its price to maximize profits, $x_{i}\left(p_{i}, p_{j}\right) p_{i}-\frac{s_{i}^{2}}{2}$, given the price of its rival $p_{j}$. The equilibrium prices are:

$$
p_{1}^{*}\left(s_{1}, s_{2}\right)=\frac{2 s_{1}\left(s_{1}-s_{2}\right) \bar{\theta}}{4 s_{1}-s_{2}} ; \quad p_{2}^{*}\left(s_{1}, s_{2}\right)=\frac{\bar{\theta} s_{2}\left(s_{1}-s_{2}\right)}{\left(4 s_{1}-s_{2}\right)}
$$

The equilibrium profits then are:

$$
\pi_{1}^{*}\left(s_{1}, s_{2}\right)=\frac{\left(p_{1}^{*}\right)^{2}}{s_{1}-s_{2}}-\frac{s_{1}^{2}}{2} \quad \text { and } \quad \pi_{2}^{*}\left(s_{1}, s_{2}\right)=\frac{s_{1}\left(p_{2}^{*}\right)^{2}}{\left(s_{1}-s_{2}\right) s_{2}}-\frac{s_{2}^{2}}{2}
$$

In the first stage, given the quality of its rival, $s_{j}$, firm $i$ chooses $s_{i}$ to maximize $\pi_{i}^{*}\left(s_{1}, s_{2}\right)$. Defining quality ratio as $\lambda=s_{2} / s_{1}$, dividing the focs, and manipulating we get the free trade equilibrium outcome:

\begin{tabular}{lll}
\hline$s_{1}^{F T}=0.25331 \bar{\theta}^{2}$ & $s_{2}^{F T}=0.04824 \bar{\theta}^{2}$ & $\lambda^{F T}=\frac{s_{2}^{F T}}{s_{1}^{F T}}=0.19043$ \\
\hline$p_{1}^{F T}=0.10766 \bar{\theta}^{3}$ & $p_{2}^{F T}=0.01025 \bar{\theta}^{3}$ & $C S^{F T}=0.04322 \bar{\theta}^{4}$ \\
\hline$\pi_{1}^{F T}=0.02444 \bar{\theta}^{4}$ & $\pi_{2}^{F T}=0.00153 \bar{\theta}^{4}$ & $T W_{f h}^{F T}=0.04475 \bar{\theta}^{4}$ \\
& & $T W_{f l}^{F T}=0.06766 \bar{\theta}^{4}$ \\
\hline
\end{tabular}

As under Cournot competition, there are two asymmetric pure strategy equilibria where one firm produces the high quality good and the other the low quality good. The domestic firm's profits and domestic welfare are higher in the equilibrium where the domestic firm is high quality.

Consider next the ex-post tariff game. Suppose that the foreign firm produces high quality. Defining $t=\bar{t} / \bar{\theta}$, the profits of the foreign and the domestic firm are $\pi_{1}=x_{1}\left(p_{1}, p_{2}\right)\left(p_{1}-\overline{t \theta}\right)-\frac{s_{1}^{2}}{2}$ and $\pi_{2}=x_{2}\left(p_{1}, p_{2}\right) p_{2}-\frac{s_{2}^{2}}{2}$, respectively. In the last stage, each firm maximizes its profits given the price of its rival. From the focs, we obtain the equilibrium prices for the foreign and the domestic firm, respectively:

$$
p_{1}^{*}=\left[\frac{2 s_{1}\left(s_{1}-s_{2}+t\right)}{4 s_{1}-s_{2}}\right] \bar{\theta} ; \quad p_{2}^{*}=\left[\frac{s_{2}\left(s_{1}-s_{2}+t\right)}{4 s_{1}-s_{2}}\right] \bar{\theta}
$$

Then the equilibrium profits are:

$$
\pi_{1}^{*}=\frac{\left(p_{1}^{*}-\overline{t \theta}\right)^{2}}{s_{1}-s_{2}}-\frac{s_{1}^{2}}{2} \quad \text { and } \quad \pi_{2}^{*}=\frac{s_{1}\left(p_{2}^{*}\right)^{2}}{\left(s_{1}-s_{2}\right) s_{2}}-\frac{s_{2}^{2}}{2}
$$

In the second stage, the government selects the tariff that maximizes domestic welfare, which from (A.2) equals: 


$$
T W=\left[\frac{s_{1}^{3}+s_{1}^{2} s_{2}-2 s_{1} s_{2}^{2}+2 s_{1}^{2} t-2 s_{1} s_{2} t-3 s_{1} t^{2}+2 s_{2} t^{2}}{2\left(4 s_{1}-s_{2}\right)\left(s_{1}-s_{2}\right)}\right] \bar{\theta}^{2}-\frac{s_{2}^{2}}{2}
$$

From the foc, the optimal ex-post tariff equals:

$$
\bar{t}^{*}=\frac{s_{1}\left(s_{1}-s_{2}\right)}{3 s_{1}-2 s_{2}} \bar{\theta}
$$

Similarly, if the foreign firm is low quality, the profits of the domestic and the foreign firm are $\pi_{1}=x_{1}\left(p_{1}, p_{2}\right) p_{1}-\frac{s_{1}^{2}}{2}$ and $\pi_{2}=x_{2}\left(p_{1}, p_{2}\right)\left(p_{2}-\overline{t \theta}\right)-\frac{s_{2}^{2}}{2}$, respectively. In the last stage, firms simultaneously set prices to maximize profits. From the focs the equilibrium prices are:

$$
p_{1}^{*}=\left[\frac{s_{1}\left(2 s_{1}-2 s_{2}+t\right)}{4 s_{1}-s_{2}}\right] \bar{\theta} ; \quad p_{2}^{*}=\left[\frac{s_{1} s_{2}+2 s_{1} t-s_{2}^{2}}{4 s_{1}-s_{2}}\right] \bar{\theta}
$$

The equilibrium profits then are:

$$
\pi_{1}^{*}=\frac{\left(p_{1}^{*}\right)^{2}}{s_{1}-s_{2}}-\frac{s_{1}^{2}}{2} \quad \text { and } \quad \pi_{2}^{*}=\frac{s_{1}\left(p_{2}^{*}-\overline{t \theta}\right)^{2}}{\left(s_{1}-s_{2}\right) s_{2}}-\frac{s_{2}^{2}}{2}
$$

In the second stage, the government selects a tariff to maximize domestic welfare, which from (A.4) equals:

$$
T W=\left[\frac{s_{1}\left(3 s_{1}^{2} s_{2}-3 s_{1} s_{2}^{2}+2 s_{1} s_{2} t-3 s_{1} t^{2}-2 s_{2}^{2} t+2 s_{2} t^{2}\right)}{2 s_{2}\left(4 s_{1}-s_{2}\right)\left(s_{1}-s_{2}\right)}\right] \bar{\theta}^{2}-\frac{s_{1}^{2}}{2}
$$

From the foc, the optimal ex-post tariff is:

$$
\bar{t}^{*}=\frac{s_{2}\left(s_{1}-s_{2}\right)}{3 s_{1}-2 s_{2}} \bar{\theta}
$$

We next show that a foreign firm producing high quality cannot be sustained in equilibrium. Note that, a high quality foreign firm, anticipating an optimal ex-post tariff which is increasing in its own quality, has no incentive to choose a quality level that is too high. The domestic firm then has an incentive to jump up in the quality ladder and become the higher quality producer. Particularly, given:

$$
\bar{t}^{*}=\frac{s_{1}\left(s_{1}-s_{2}\right)}{3 s_{1}-2 s_{2}} \bar{\theta}
$$

the firms' equilibrium prices are (from (A.2)):

$$
p_{1}^{*}=\frac{4 s_{1}\left(2 s_{1}-s_{2}\right)\left(s_{1}-s_{2}\right)}{\left(4 s_{1}-s_{2}\right)\left(3 s_{1}-2 s_{2}\right)} \bar{\theta} ; \quad p_{2}^{*}=\frac{2 s_{2}\left(s_{1}-s_{2}\right)\left(2 s_{1}-s_{2}\right)}{\left(4 s_{1}-s_{2}\right)\left(3 s_{1}-2 s_{2}\right)} \bar{\theta}
$$

The equilibrium profits then are: 


$$
\pi_{1}^{*}=\frac{\left(p_{1}^{*}-t \bar{\theta}\right)^{2}}{s_{1}-s_{2}}-\frac{s_{1}^{2}}{2} \text { and } \pi_{2}^{*}=\frac{s_{1}\left(p_{2}^{*}\right)^{2}}{\left(s_{1}-s_{2}\right) s_{2}}-\frac{s_{2}^{2}}{2}
$$

In the first stage, each firm maximizes its profits taking the quality of its rival as given. Defining $\lambda=s_{1} / s_{2}$, and dividing the focs, we obtain the equilibrium quality ratio, $\lambda^{*}=s_{1}^{*} / s_{2}^{*}=2.04551$. Then from the focs we obtain the (candidate) equilibrium outcome: $s_{1}^{*}=0.12160 \bar{\theta}^{2}, s_{2}^{*}=0.05945 \bar{\theta}^{2}, p_{1}^{*}=0.05291 \bar{\theta}^{3}, p_{2}^{*}=$ $0.01293 \bar{\theta}^{3}, \quad \pi_{1}^{*}=0.00052 \bar{\theta}^{4}, \quad \pi_{2}^{*}=0.00374 \bar{\theta}^{4}, \quad \bar{t}^{*}=0.03073 \bar{\theta}^{3}, \quad C S^{*}=$ $0.02215 \bar{\theta}^{4}$ and $T W^{*}=0.03686 \bar{\theta}^{4}$. Note, however, that this cannot be an equilibrium configuration of qualities.

Suppose that the foreign firm chooses $s_{l}=s_{1}^{*}=0.12160 \bar{\theta}^{2}$. Then the domestic firm has an incentive to switch qualities and produce a higher quality $s_{h}>s_{l}$. In this case the optimal government's tariff will be:

$$
t^{*}=\frac{s_{l}\left(s_{h}-s_{l}\right)}{3 s_{h}-2 s_{l}}
$$

and the profits of the domestic firm are:

$$
\pi_{h}^{*}=\frac{\left(p_{h}^{*}\right)^{2}}{s_{h}-s_{l}}-\frac{s_{h}^{2}}{2}
$$

where:

$$
p_{h}^{*}=\frac{3 s_{h}\left(2 s_{h}-s_{l}\right)\left(s_{h}-s_{l}\right)}{\left(3 s_{h}-2 s_{l}\right)\left(4 s_{h}-s_{l}\right)} \bar{\theta}
$$

Plotting $\pi_{h}^{*}\left(s_{h}, s_{l}\right)$ for $s_{h}>s_{l}=0.12160 \bar{\theta}^{2}$, it can be easily seen that for sufficiently high $s_{h}$, the domestic firm's profits are higher than $\pi_{2}^{*}=0.00374 \bar{\theta}^{4}$ (In fact, the maximum profits are approximately equal to $0.0213 \bar{\theta}^{4}$ ).

Further, we check if the foreign firm has an incentive to remain the high quality producer by selecting a quality different from $s_{1}^{*}$. Clearly, if it chooses a quality $s_{1}<s_{1}^{*}$, the domestic firm has a strong incentive to become the high quality producer. On the other hand, the foreign firm has no incentive to choose a quality higher than $s_{1}^{*}$, since in this case its (net) profits are lower than if it were producing the low quality good (see below). It can be checked that, for all these values of $s_{1}$, the domestic firm has an incentive to switch positions in the quality ladder and become the high quality producer.

We next show that the domestic firm producing high quality and the foreign firm producing low quality is the equilibrium configuration of qualities. Since:

$$
t^{*}=\frac{s_{2}\left(s_{1}-s_{2}\right)}{3 s_{1}-2 s_{2}}
$$

from (A.4) we get the equilibrium prices and profits: 


$$
p_{1}^{*}=\frac{3 s_{1}\left(2 s_{1}-s_{2}\right)\left(s_{1}-s_{2}\right)}{\left(3 s_{1}-2 s_{2}\right)\left(4 s_{1}-s_{2}\right)} \bar{\theta} ; \quad p_{2}^{*}=\frac{s_{2}\left(s_{1}-s_{2}\right)\left(5 s_{1}-2 s_{2}\right)}{\left(3 s_{1}-2 s_{2}\right)\left(4 s_{1}-s_{2}\right)} \bar{\theta}
$$

and

$$
\pi_{1}^{*}=\frac{\left(p_{1}^{*}\right)^{2}}{s_{1}-s_{2}}-\frac{s_{1}^{2}}{2} ; \quad \pi_{2}^{*}=\frac{s_{1}\left(p_{2}^{*}-\overline{t \theta}\right)^{2}}{\left(s_{1}-s_{2}\right) s_{2}}-\frac{s_{2}^{2}}{2}
$$

In the quality selection stage, each firm maximizes its profits taking the quality of its rival as given. Defining $\lambda=s_{1} / s 2$, from the first order conditions we obtain the equilibrium ratio of qualities $\lambda^{*}=s_{1}^{*} / s_{2}^{*}=38.3633$. Then the equilibrium outcomes are:

\begin{tabular}{lll}
\hline$s_{1}^{*}=0.25004 \bar{\theta}^{2}$ & $s_{2}^{*}=0.00652 \bar{\theta}^{2}$ & $\bar{t}^{*}=0.00215 \bar{\theta}^{3}$ \\
\hline$p_{1}^{*}=0.12310 \bar{\theta}^{3}$ & $p_{2}^{*}=0.00268 \bar{\theta}^{3}$ & $C S^{*}=0.03224 \bar{\theta}^{4}$ \\
\hline$\pi_{1}^{*}=0.03097 \bar{\theta}^{4}$ & $\pi_{2}^{*}=0.00002 \bar{\theta}^{4}$ & $T W^{*}=0.06339 \bar{\theta}^{4}$ \\
\hline
\end{tabular}

Finally, it can be checked that no firm has an incentive to switch qualities. As a result, this is the unique equilibrium outcome under optimal ex-post tariffs.

Comparing with free trade, if the foreign firm is high quality under free trade, the imposition of the ex-post optimal tariff results in an increase in domestic welfare $\left(T W_{f h}^{F T}=0.04475 \bar{\theta}^{4}<T W^{*}=0.06339 \bar{\theta}^{4}\right)$. In contrast, if the foreign firm is low quality under free trade, the ex post tariff decreases domestic welfare (since $T W_{f l}^{F T}=0.06766 \bar{\theta}^{4}>T W^{*}$ ). These results are due to two opposing effects. First, under ex-post optimal tariffs both the qualities offered in the domestic market are lower than under free trade, i.e. $s_{1}^{*}=0.25004 \bar{\theta}^{2}<s_{1}^{F T}=0.25331 \bar{\theta}^{2}$ and $s_{2}^{*}=$ $0.00652 \bar{\theta}^{2}<s_{2}^{F T}=0.04824 \bar{\theta}^{2}$. The lower qualities result in lower consumer surplus. Second, there is a positive rent shifting effect due to the imposition of the tariff. The latter dominates the negative quality downgrading effect whenever the domestic firm switches position in the quality ladder. If no quality reversal is observed, the quality downgrading effect is dominant, thus resulting in lower domestic welfare.

Turning to the ex-ante tariff game, we distinguish between prohibitive and non-prohibitive tariffs. We know that a prohibitive tariff, which results in a domestic monopoly, gives us domestic welfare of $\left(T W_{M}^{*}=\right) 0.0625 \bar{\theta}^{4}$. To determine the optimal non-prohibitive tariff, we first consider the case where the foreign firm is high quality. In the second stage, given the government's tariff on imports, the domestic and the foreign firm select their quality level to maximize profits. Defining $s_{2} / s_{1}=\lambda$ and $\mu=t / s_{1}$, the focs from (A.1) can be expressed as $s_{1}(\lambda, \mu)$ and $s_{2}(\lambda, \mu)$. Using the focs and the zero profit condition for the foreign 
firm and solving for $\left(s_{1}, s_{2}, t\right)$ we obtain $s_{1 m}=0.2451 \bar{\theta}^{2}, s_{2 m}=0.07433 \bar{\theta}^{2}$ and the maximum permissible tariff $t_{m}=0.04525 \theta^{2}$ (with the associated quality ratio being $\lambda_{\underline{m}}=0.30328$ ). Hence, the relevant interval for the import tariff is $0 \leq \bar{t} \leq$ $0.04525 \theta^{3}$, with the associated interval of quality ratios, $\lambda^{F T}=0.19043 \leq \lambda \leq$ 0.30328 .

Using steps similar to the Cournot case, we can see that $s_{2}$ is increasing in $t$, while $s_{1}$ is initially (slightly) increasing and then decreasing in $t$. The profits of the high-quality foreign firm $\tilde{\pi}_{1}$ decrease with the tariff and reach zero for the maximum tariff $t_{m}$, while the profits of the domestic firm $\pi_{2}$ increase with the tariff and are equal to $0.00330 \theta^{4}$ for $t_{m}$. Further, consumer surplus decreases with the tariff. Finally, domestic welfare increases with the tariff and reaches its maximum value $0.05886 \bar{\theta}^{4}$ at the maximum tariff $t_{m}=0.04525 \bar{\theta}^{2}$. However, since the optimal non-prohibitive tariff results in lower domestic welfare than the prohibitive tariff, the government's optimal ex-ante tariff is the prohibitive tariff. The latter is much higher than the optimal ex-post tariff $\bar{t}^{*}=0.00215 \bar{\theta}^{3}$. More interestingly, domestic welfare under the ex-ante optimal tariff is lower than under the ex-post optimal tariff $\left(T W_{M}^{*}=0.0625 \bar{\theta}^{4}<T W^{*}=0.06339 \bar{\theta}^{4}\right)$.

Now, consider the case where the foreign firm is low quality. In this case domestic welfare under free trade is (strictly) higher than under the ex-post optimal tariff $\left(T W_{f l}^{F T}=0.06766 \bar{\theta}^{4}>T W^{*}\right)$. The optimal ex-ante tariff results in a level of domestic welfare at least as high as under free trade. In this case domestic welfare is higher under ex-ante tariffs than under ex-post tariffs. In fact, it can be checked that the optimal ex-ante tariff is $\tilde{t}=0.00565 \bar{\theta}^{2}$ and the equilibrium outcome in this case is given by:

\begin{tabular}{lll}
\hline$\tilde{s}_{1}^{H}=0.25231 \bar{\theta}^{2}$ & $\tilde{s}_{2}^{F}=0.00455 \bar{\theta}^{2}$ & $\tilde{\bar{t}}=0.00565 \bar{\theta}^{3}$ \\
\hline$\tilde{p}_{1}^{H}=0.109767 \bar{\theta}^{3}$ & $\tilde{p}_{2}^{F}=0.01272 \bar{\theta}^{3}$ & \\
\hline$\tilde{\pi}_{1}^{H}=0.000306 \bar{\theta}^{4}$ & $\tilde{\pi}_{2}^{F}=0.02643 \bar{\theta}^{4}$ & $\widetilde{T W}=0.068436 \bar{\theta}^{4}$ \\
\hline
\end{tabular}

Q.E.D.

\section{References}

Brander, J., Spencer, B., 1984. Tariff protection and imperfect competition. In: Kierzkowski, H. (Ed.), Monopolistic Competition and International Trade. Oxford University Press, Oxford, Chapter 12.

Brander, J., Spencer, B., 1985. Export subsidies and international market share rivalry. Journal of International Economics 18, 83-100.

Collie, D., 1991. Export subsidies and countervailing tariffs. Journal of International Economics 31, 309-324. 
Dixit, A., 1988. Anti-dumping and countervailing duties under oligopoly. European Economic Review $32,56-68$.

Eaton, J., Grossman, G., 1986. Optimal trade and industrial policy. Quarterly Journal of Economics 101, 383-406.

Greenaway, D., Hine, R., Milner, C., 1990. Country specific factors and the pattern of horizontal and vertical intra industry trade in the UK. Weltwirtschaftliches Archiv 130 (1), 77-100.

Grossman, G., 1988. Strategic export promotion: a critique. In: Krugman, P. (Ed.), Strategic Trade Policy and the New International Economics. MIT Press, Cambridge, MA.

Herguera, I., Kujal, P., Petrakis, E., 1997. Non-Credible Policies and Leapfrogging in Vertically Differentiated Industries. Working Paper 97-73. Universidad Carlos III.

Herguera, I., Kujal, P., Petrakis, E., 2000. Quantity restrictions and endogenous quality choice. International Journal of Industrial Organization 18, 1259-1277.

Hwang, H.S., Schulman, C.T., 1993. Strategic non-intervention and the choice of trade policy for international oligopoly. Journal of International Economics 34, 73-93.

Leahy, D., Neary, J.P., 1994. Time consistency, learning by doing and infant-industry protection: The linear case. The Economic and Social Science Review 26 (1), 59-68.

Leahy, D., Neary, J.P., 1996. International R\&D rivalry and industrial strategy without government commitment. Review of International Economics 4 (3), 322-338.

Leahy, D., J.P. Neary, 1999. Learning by doing, precommitment and infant-industry protection. Review of Economic Studies.

Neary, J.P., 1991. Export subsidies and price competition. In: Helpman, E., Razin, A. (Eds.), International Trade and Trade Policy. MIT Press, Cambridge, MA.

Motta, M., 1993. Endogenous quality choice: price vs. quantity competition. Journal of Industrial Economics 1, 113-131.

Shaked, A., Sutton, J., 1982. Relaxing price competition through product differentiation. Review of Economic Studies 49, 3-13.

Shaked, A., Sutton, J., 1983. Natural oligopolies. Econometrica 51 (5), 1469-1483.

Shaked, A., Sutton, J., 1984. Natural oligopolies and international trade. In: Kierzkowski, H. (Ed.), Monopolistic Competition and International Trade. Oxford University Press, Oxford, pp. 34-50.

Sutton, J., 1991. Sunk Costs and Market Structure. MIT Press, Cambridge, MA.

Tirole, J., 1989. The Theory of Industrial Organization. MIT Press, Cambridge, MA. 